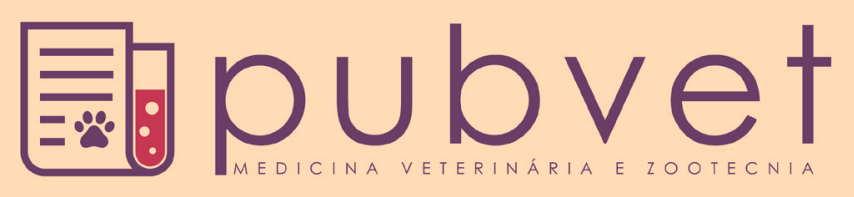

HTTP://DX.DOI.ORG/10.22256/PUBVET.V11N7.676-679

\title{
Correção cirúrgica de fenda palatina traumática em gato: Relato de caso
}

\section{Hannah Martins Oliveira Gonçalves da Silva ${ }^{1 *}$, Catarina Rafaela Alves da Silva ${ }^{2}$, Francisco Lima Silva ${ }^{3}$, Lianna Martins Oliveira Gonçalves da Silva ${ }^{4}$}

${ }^{1}$ Médica Veterinária, Teresina-PI, Brasil.E-mail: hannah martins@hotmail.com

${ }^{2}$ Doutora em Ciência Animal pela UFPI. Residente de Anestesiologia Veterinária do HVU-UFPI, Teresina-PI, Brasil. ${ }^{3}$ Professor da Universidade Federal do Piauí, Departamento de Clínica e Cirurgia Veterinária. Teresina-PI, Brasil.

${ }^{4}$ Médica Veterinária, Teresina-PI, Brasil.

RESUMO. A maioria dos defeitos no palato, independente de serem consequências de traumas, infecções crônicas, neoplasias ou alterações congênitas, só pode ser corrigida cirurgicamente, visto que existe o risco de aspiração de alimentos para a via respiratória. $\mathrm{O}$ presente trabalho tem por objetivo relatar o caso de um gato atendido no HVU - UFPI com fenda palatina secundária por trauma e que foi corrigido cirurgicamente utilizando a técnica de retalho bipediculado deslizante (técnica de Von Langebeck).

Palavras chave: palato, técnica cirúrgica, trauma

\section{Surgical correction of traumatic palatine cleft in cat: Case report}

\begin{abstract}
The majority of defects in the palate, regardless of the consequences of trauma, chronic infections, neoplasia or congenital abnormalities, can only be corrected surgically, since there is a risk of aspiration of food into the respiratory tract. The present study aims to report the case of a cat treated in the HVU - UFPI with secondary cleft palate by trauma and that was surgically corrected using the sliding bipediculate flap technique (Von Langebeck technique).
\end{abstract}

Keywords: palate surgical technique, trauma

\section{Corrección quirúrgica de paladar hendido por traumatismo en gato: Reporte de un caso}

RESUMEN. La mayoría de los defectos en el paladar, independientemente de ser consecuencia de traumas, infecciones crónicas, neoplasias o alteraciones congénitas, sólo puede ser corregida quirúrgicamente, ya que existe el riesgo de aspiración de alimentos para la vía respiratoria. El presente trabajo tiene por objetivo reportar el caso de un gato atendido en el HVU - UFPI con paladar hendido por causa secundaria (trauma) y que fue corregido quirúrgicamente utilizando la técnica de técnica de Von Langebeck.

Palabras clave: paladar, técnica quirúrgica, trauma

\section{Introdução}

O palato é uma estrutura localizada dorsalmente na cavidade oral, sendo responsável pela sua separação da cavidade nasal e orofaríngea. É constituído pelo palato primário (lábios, crista alveolar incisiva e pré-maxila), palato secundário (ossos palatino, maxilares e incisivos) e palato mole, que tem início no último molar e se estende até a cripta da tonsila (Bojrab, 2005).

O palato duro é caracterizado por um epitélio pavimentoso estratificado queratinizado ou 
paraqueratinizado, papilas conjuntivas numerosas, profundas e ramificadas, lâmina própria rica em fibras colágenas e ausência de fibras elásticas. Apresenta uma união firme e imóvel da mucosa (lamina própria) ao periósteo, denominando-se mucoperiósteo. A submucosa está presente apenas nas regiões laterais do palato: região anterolateral (zona adiposa), onde a submucosa é predominantemente constituída de tecido adiposo, e região posterolateral (zona glandular) onde a submucosa é predominantemente constituída por tecido glandular do tipo mucoso. O palato mole apresenta um epitélio do tipo estratificado pavimentoso não queratinizado, possui, além da lâmina própria, uma camada distinta de fibras elásticas que separa a lâmina própria da submucosa. A submucosa é formada de tecido conjuntivo, relativamente frouxo com as glândulas salivares do tipo mucoso. A mucosa está firmemente aderida aos planos profundos através das fibras colágenas (Junqueira and Carneiro, $\underline{2013}$ ).

A irrigação sanguínea dessa região origina-se de ramos das artérias carótidas comuns. Os pares de artérias palatinas maiores e menores são importantes. Duas ou três veias emergem do forame palatino maior, rostralmente à face caudal do quarto pré-molar superior, equidistante da linha mediana e da arcada dentária. As artérias palatinas maiores direita e esquerda se anastomosam caudalmente aos dentes incisivos. As artérias palatinas menores entram no palato, caudalmente ao último molar e lateralmente à artéria palatina maior, cursando caudomedialmente então, para ramificarem-se no palato duro caudal e palato mole (Fossum, 2014).

As fissuras podem envolver somente os lábios, chamadas fissuras primárias, ou os palatos duros e moles, fissuras secundárias. A maioria das fissuras necessita de uma reconstrução cirúrgica, mas a deiscência é comum e em alguns casos são necessárias várias cirurgias para se obter o fechamento completo (Birchard and Sherding, $\underline{2008)}$.

O fechamento incompleto do palato primário ou secundário pode ser hereditário, nutricional, hormonal, mecânico e por fator tóxico. A fissura palatina primária sozinha é rara; entretanto, a fissura palatina secundária pode ocorrer sozinha ou em combinação com fissuras primárias. Sinais de rinite e outras infecções respiratórias são comuns (Fossum, 2014). A maioria dos defeitos no palato, independente de serem consequências de traumas, infecções crônicas, neoplasias ou alterações congênitas, só pode ser corrigida cirurgicamente, visto que existe o risco de aspiração de alimentos para a via respiratória. A dimensão da lesão e a facilidade de acesso à região afetada é que vão determinar qual técnica cirúrgica é a mais recomendada para cada caso (Hette and Rahal, 2004), pois a mesma pode variar de uma pequena abertura no palato mole, até uma fissura completa desde o palato mole até a papila incisiva (Silva et al., 2006).

$\mathrm{O}$ reparo bem-sucedido da fissura requer um fechamento bem sustentado, hermético e livre de tensão. As áreas de onde os retalhos são coletados cicatrizam por segunda intenção em 2 a 3 semanas. Alimento pastoso deve ser fornecido por no mínimo duas semanas após a cirurgia e não se deve permitir que o animal morda objetos duros. A alimentação via esofagostomia por 7 a 14 dias pode facilitar a cicatrização. As complicações mais comuns são a deiscência e a subseqüente cicatrização incompleta de fístula oronasal (Fossum, 2014). O sucesso da cirurgia reconstrutiva depende, em larga escala, da preservação da vascularização dos enxertos (Smith, 2000) e da capacidade do enxerto resistir ao estresse mecânico induzido pela mastigação, deglutição e movimentação traumática permanente da língua no palato regional (Sivacolundhu, 2007). O prognóstico é favorável nos pacientes com pequenas fendas corrigidas cirurgicamente (Silva et al., 2006).

O presente trabalho tem por objetivo relatar o caso de um gato atendido no HVU - UFPI com fenda palatina secundária por trauma e que foi corrigido cirurgicamente utilizando a técnica de retalho bipediculado deslizante (técnica de Von Langebeck).

\section{Descrição do caso}

Foi atendido no HVU-UFPI, um gato SRD, aproximadamente 2 anos, macho, não castrado, pesando $2 \mathrm{kgs}$, vítima de trauma. O proprietário relatou que o animal tinha livre acesso à rua e na manhã daquele dia retornou pra casa com a boca entreaberta, muito sangue na região do focinho e bastante cansado. No exame físico, notou-se uma disjunção da sínfise mandibular, epistaxe, foi auscultado secreção pulmonar, temperatura retal $39^{\circ} \mathrm{C}$ e o animal estava bastante estressado.

O animal foi internado para administração de fluido intravenoso (Sol. fisiológica de cloreto de sódio a $0,9 \%)$, amoxicilina (20 mg/ $\mathrm{kg})$ BID, 
cetoprofeno (2 mg/kg) SID, tramadol $(4 \mathrm{mg} / \mathrm{kg})$ QID e foram coletados hemograma e bioquímicos para avaliação de risco anestésico e encaminhamento do animal para a cirurgia de estabilização de sínfise mandibular três dias depois da admissão no hospital.

No dia da cirurgia o animal apresentava uma secreção mucosa pelas narinas e na cavidade oral. Foram utilizados na MPA, acepromazina 0,2\% $(0,015 \mathrm{mg} / \mathrm{kg})$, midazolam $(0,3 \mathrm{mg} / \mathrm{kg})$, cetamina $(7 \mathrm{mg} / \mathrm{kg})$ e morfina $(0,2 \mathrm{mg} / \mathrm{kg})$. A indução foi feita com propofol $(4 \mathrm{mg} / \mathrm{kg})$. No momento da intubação para a anestesia inalatória, verificou-se a presença de bastante secreção mucosa no palato do animal, após a limpeza, verificou-se uma fenda palatina secundária acometendo $\mathrm{o}$ palato duro (Figura 1).

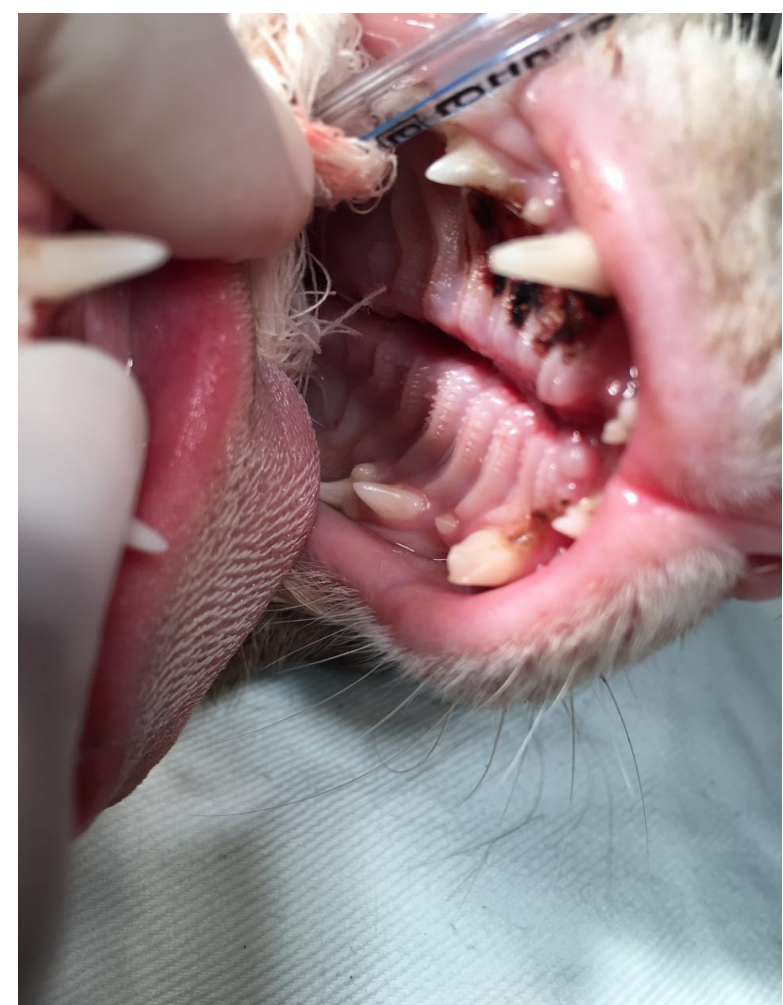

Figura 1. Fenda palatina secundária em gato. Fonte: Arquivo pessoal.

Após breve reunião da equipe cirúrgica para o replanejamento do procedimento cirúrgico, optouse por fazer a técnica de retalho bipediculado deslizante (técnica de Von Langebeck) para a correção da fissura palatina após a estabilização da sínfise mandibular. $\mathrm{O}$ animal foi mantido na anestesia inalatória com isofluorano.

A técnica foi feita de acordo com Silva et al. (2006) e Fossum (2014) foi feita a antissepsia da cavidade oral com Clorexidine a $0,12 \%$, incisouse as margens do defeito $\mathrm{e}$ incisou-se bilateralmente ao longo das margens da arcada dentária. Elevou-se a camada mucoperiosteal em ambos os lados do defeito com um elevador periosteal, evitando danos as artérias palatinas maiores. Deslizaram-se os retalhos mucoperiosteais sobre o defeito e utilizou-se a sutura simples descontínua com o ácido poliglicólico 4-0. Deixou-se o palato duro desnudo próximo as arcadas para cicatrizar por segunda intenção (Figuras 2 e 3 ).

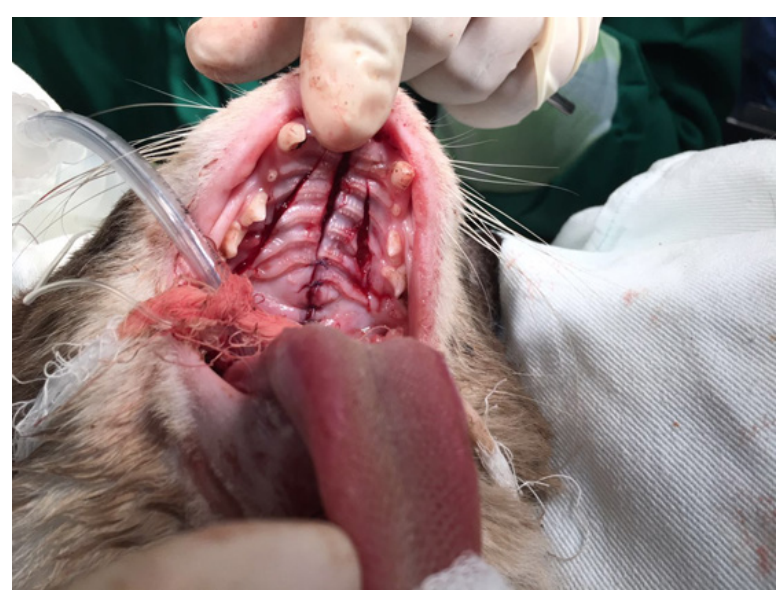

Figura 2. Início da sutura da fenda palatina. Fonte: Arquivo pessoal.

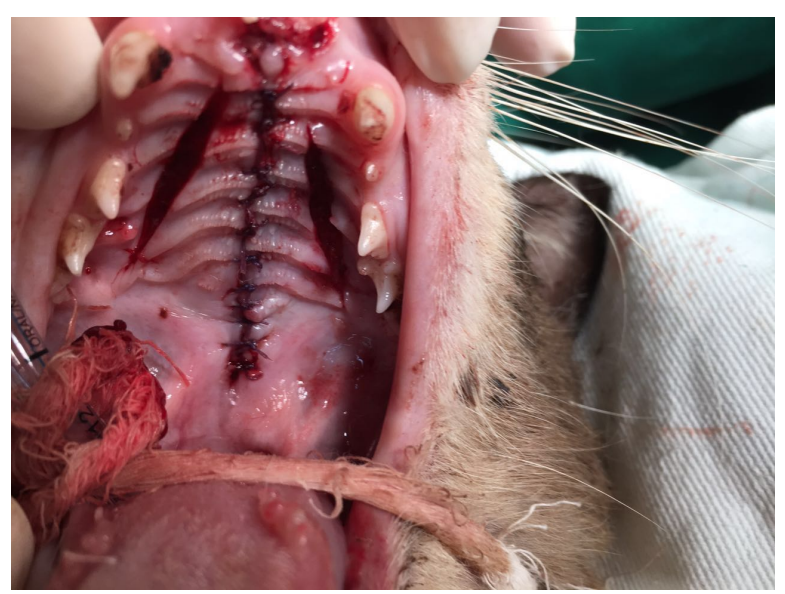

Figura 3. Aspecto final da cirurgia. Fonte: Arquivo pessoal.

No pós-operatório foram acrescentados metronidazol $(15 \mathrm{mg} / \mathrm{kg})$ BID e borrifadas de Hexomedine na cavidade oral ao protocolo inicial de tratamento. A alimentação foi exclusivamente pastosa, apesar disso, 72 horas após o procedimento o animal ainda se recusava a comer sozinho, somente auxiliado através de seringa. Optou-se por colocar uma sonda nasoesofágica para um melhor suporte nutricional, foi observado que a maioria dos pontos já haviam sido retirada; apesar disso o palato estava bem cicatrizado (Figura 4). Dois dias após a sonda, o animal voltou ao seu comportamento normal, inclusive se 
alimentando sem ajuda, a sonda foi retirada e o animal teve alta.

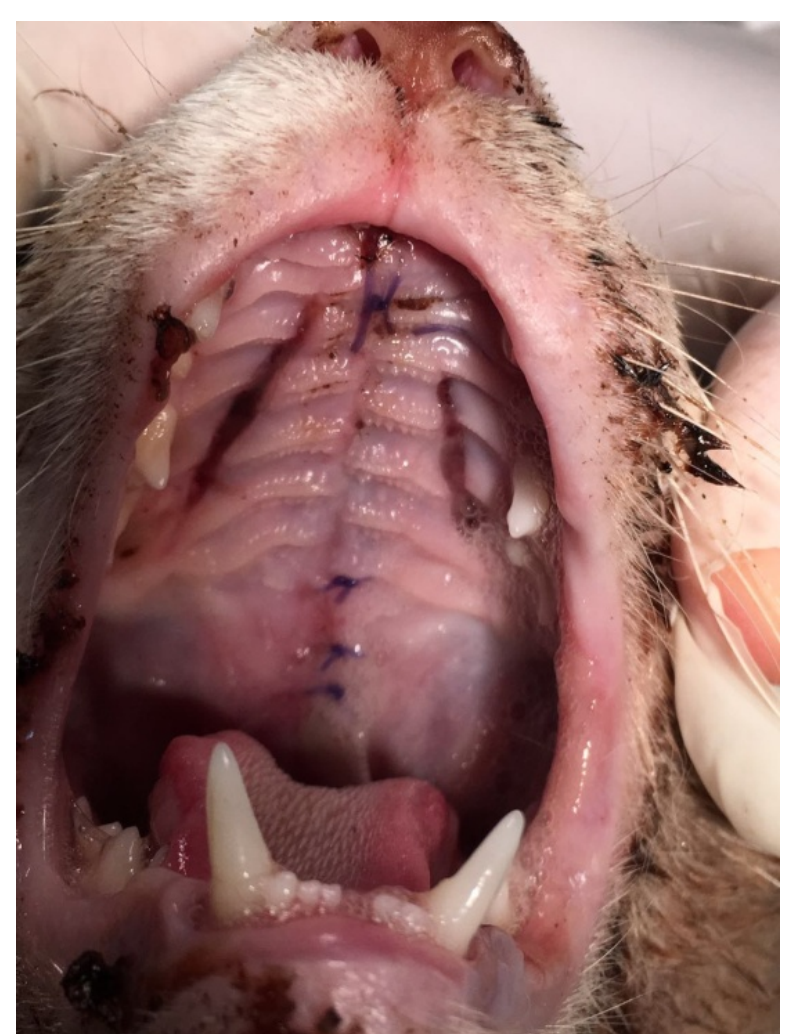

Figura 4. Aspecto da cavidade oral 3 dias após a cirurgia. Fonte: Arquivo pessoal.

De acordo com Silva et al. (2006) as técnicas cirúrgicas podem ser bem empregadas na correção de defeitos palatinos não só como último recurso, mas como efetivos de primeira escolha na promoção do conforto e do bem-estar dos pacientes acometidos.

\section{Considerações finais}

A equipe cirúrgica deve estar sempre preparada para lidar com os imprevistos que possam vir a acontecer nos procedimentos cirúrgicos e ter a sabedoria e o conhecimento necessários para tomar a melhor decisão sempre objetivando o bem estar do paciente e a resolução do problema. Nesse caso, o conhecimento da técnica a ser empregada fez toda a diferença.
A técnica de retalho bipediculado deslizante (técnica de Von Langebeck) se mostrou bastante eficiente para a correção da fissura palatina secundária, não houve deiscência e o animal se recuperou bem.

\section{Referências Bibliográficas}

Birchard, S. J. \& Sherding, R. G. 2008. Manual Saunders: clínica de pequenos animais, São Paulo.

Bojrab, M. J. 2005. Técnicas atuais em cirurgia de pequenos animais. Editora Roca, São Paulo.

Fossum, T. W. 2014. Cirurgia de pequenos animais, 4 edn. Elsevier Brasil, São Paulo.

Hette, K. \& Rahal, S. C. 2004. Defeitos congênitos do palato em cães. Clínica Veterinária, 50, 3040.

Junqueira, L. C. \& Carneiro, J. C. 2013. Histologia Básica, 12 ed. edn. Guanabara Koogan, Rio de Janeiro.

Silva, M. R., Sousa Aleixo, G. A., Sá, F. B. \& Coelho, M. C. C. 2006. Redução de fenda palatina secundária em um gato. Ciência Veterinária nos Trópicos, 9, 97-101.

Sivacolundhu, R. K. 2007. Use of local and axial pattern flaps for reconstruction of the hard and soft palate. Clinical Techniques in Small Animal Practice, 22, 61-69.

Smith, M. M. 2000. Oronasal fistula repair. Clinical techniques in small animal practice, 15, 243-250.

Article History:

Received 9 February 2017

Accepted 20 April 2017

Available on line 10 June 2017

License information: This is an open-access article distributed under the terms of the Creative Commons Attribution License 4.0, which permits unrestricted use, distribution, and reproduction in any medium, provided the original work is properly cited. 